\title{
Color Assessment of Granitic Rocks and Implications For Their Ornamental Utilization
}

\author{
Luís M. O. Sousa, ${ }^{1 \star}$ Bruno M. M. Gonçalves ${ }^{2}$ \\ ${ }^{1}$ Department of Geology, Universidade de Trás-os-Montes e Alto Douro, Apartado 1013, 5001-801 Vila Real, Portugal \\ ${ }^{2}$ R\&D Department, Transgranitos - Mármores e Granitos do Alto Tâmega, Lda., Apartado 26, Telões, 5450-909 Vila Pouca de Aguiar, Portugal
}

Received 9 November 2009; revised 1 November 2010; accepted 9 November 2010

Abstract: The purpose of this study is to evaluate the factors affecting the assessment of granite color, such as grain size and texture, and to propose a methodology for this task which would reduce the margin of error associated with this procedure. For this purpose, an evaluation was carried out on the color of several granites with different textures used in the dimensional stone industry to highlight the importance of the sample area, the number of measurements per sample and the aperture of the equipment. A colorimeter was used to measure the granite color according to the CIE-L*a*b* and CIE-L*C* ${ }_{a b} h_{a b}$ systems, in both large slabs and small samples selected in a processing plant of ornamental granites. Granite color characteristics from large slabs had to be obtained with at least 60 shots due to the variation between different slabs. Therefore, several samples are needed for granite characterization. The color of gray granites does not vary significantly. Nevertheless, the more weathered granites show significant differences which are more evident in the $b^{*}$-parameter, or the yellow-blue component, which allow the use of the colorimeter for quality control. By doing so significant differences among the rock pieces used in a single building can be avoided. There were no significant differences found in the color parameters from distinct apertures. However, due to the heterogeneity of the granite the color is evaluated better with larger apertures. (C) 2011 Wiley Periodicals, Inc. Col Res Appl, 37, 375-383, 2012; Published online 15 July 2011 in Wiley Online Library (wileyonlinelibrary.com). DOI 10.1002/col.20681

Key words: color measurement; granite; CIE system

*Correspondence to: Luís M. O. Sousa (e-mail: 1sousa@utad.pt).

(C) 2011 Wiley Periodicals, Inc.

\section{INTRODUCTION}

The ornamental stone industry needs to reach high-level quality standards to compete with products like ceramic and wood. The products obtained from stone must be reasonably priced, fashionable and have good physicalmechanical properties. ${ }^{1}$ Color is one of the factors that most influences the aesthetic aspect of the rocks, but there are others such as grain size, grain shape, petrofabric and gloss. ${ }^{2,3}$ The market value of the rocks is extremely dependent on these factors. Therefore, the texture variations must be as small as possible as the market requires a product with minimal or no variations. Quantifying the natural variations of the rocks is necessary for evaluating the color and textural variations of the slabs applied in a specific work. Color in rocks is one of the most difficult factors to quantify because of both the natural variations in the mineralogical distribution in a single piece and the weathering state of rock that changes the color of some minerals. In the dimensional stone industry, common terms are usually used for rock color characterization, such as gray, pink, red, black (and the related terms, like pinkish), but the concept of such colors is different from one person to another, and commercial conflicts are frequent because of the lack of a precise language. The use of an automatic color classification, such as the CIE system, is widespread in research ${ }^{4-8}$ because it adds consistency in color assessment.

Small changes in the polishing are expected according to the granites and/or variation in the process over time, with consequences in the quality of the polishing of the slabs. These variations are small and industrially acceptable but may change the gloss/roughness and, therefore, the color. ${ }^{5,9}$ As the industrial process always tries to achieve the best results (maximum polishing), we assume that gloss/roughness does not interfere with the color characteristics and all variations reflect the mineralogical and textural properties of the granites. 
TABLE I. Petrographic characteristics of the studied granites.

\begin{tabular}{llll}
\hline Commercial name & \multicolumn{1}{c}{ Source } & \multicolumn{1}{c}{ Granite type } & Color \\
\hline Amarelo Real (AR) & Vila Pouca de Aguiar & Two micas, hypidiomorphic granular & Brown yellowish \\
Branco Real (BR) & Vila Pouca de Aguiar & Two micas, hypidiomorphic granular & Greyish \\
Cinza Telões (CT) & Vila Pouca de Aguiar & Biotitic, porphyritic tendency, hypidiomorphic granular & Dark gray \\
Pedras Salgadas (PS) & Vila Pouca de Aguiar & Biotite, slight porphyritic tendency, hypidiomorphic granular & Gray \\
Azul Tragal (AT) & Mogadouro & Biotitic, porphyritic tendency & Gray \\
Branco Coral (BC) & Viseu & Biotitic, porphyritic & Beige \\
Branco Cristal (BCr) & Spain & Biotitic, hypidiomorfic granular & Whitish \\
Branco Micaela (BM) & Aguiar da Beira & Two micas, hypidiomorfic granular & Gray \\
\hline
\end{tabular}

The samples were obtained in a real situation in the processing plant of Transgranitos-Mármores e Granitos do Alto Tâmega, Lda., located in Vila Pouca de Aguiar, in the north of Portugal.

\section{MATERIAL AND METHODS}

Eight granites used in the dimensional stone industry originating from the north of Portugal (seven granites) and
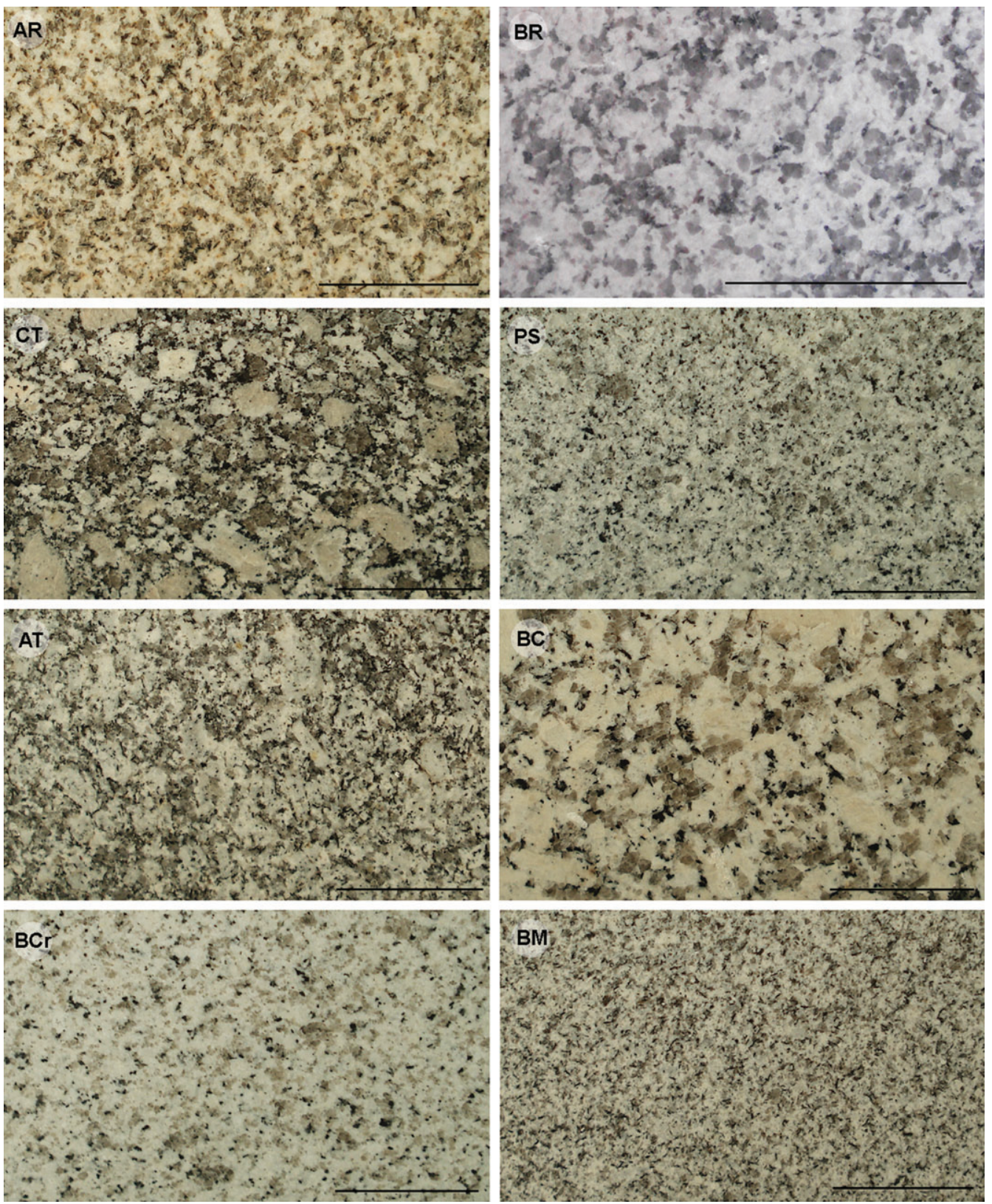

FIG. 1. Macroscopic characteristics of the eight granites used in this study (the bar on the photos is $5 \mathrm{~cm}$ long; granite abbreviations in Table I). 
TABLE II. Grain size and percentages of the main mineralogical families (granite abbreviations in Table I).

\begin{tabular}{|c|c|c|c|c|c|c|c|c|c|c|c|c|c|}
\hline \multirow[b]{2}{*}{ Granite } & \multicolumn{3}{|c|}{ Quartz } & \multicolumn{3}{|c|}{ Feldspars } & \multicolumn{3}{|c|}{ Biotite } & \multicolumn{3}{|c|}{ Muscovite } & \multirow[b]{2}{*}{ Grain size $(\mathrm{mm})$} \\
\hline & Size (mm) & $\%$ & Color & Size (mm) & $\%$ & Color & size $(\mathrm{mm})$ & $\%$ & Color & Size $(\mathrm{mm})$ & $\%$ & Color & \\
\hline AR & $1.7 \pm 1.0$ & 36.3 & Light brown & $2.3 \pm 1.9$ & 52.1 & Yellowish & $0.7 \pm 0.4$ & 2.7 & Black & $1.7 \pm 0.7$ & 9.0 & Gray & $1.8 \pm 1.5$ \\
\hline $\mathrm{BR}$ & $2.4 \pm 1.4$ & 43.1 & Gray & $3.3 \pm 1.3$ & 49.1 & Light gray & $0.7 \pm 0.5$ & 2.7 & Black & $1.4 \pm 0.9$ & 5.1 & Gray & 1.9 \\
\hline CT & $1.4 \pm 0.7$ & 33.2 & Light brown & $2.3 \pm 2.4$ & 57.0 & Beige & $0.6 \pm 0.4$ & 9.4 & Black & $0.5 \pm 0.3$ & 0.4 & Gray & 1.7 \\
\hline PS & $1.3 \pm 0.9$ & 41.1 & Light brown & $1.6 \pm 1.1$ & 47.5 & Gray & $0.8 \pm 0.4$ & 7.0 & Black & $1.1 \pm 0.7$ & 4.4 & Gray & $1.4 \pm 1.0$ \\
\hline AT & $1.8 \pm 1.0$ & 39.2 & Light brown & $3.0 \pm 2.1$ & 53.8 & Gray & $0.5 \pm 0.4$ & 6.5 & Black & $0.7 \pm 0.2$ & 0.5 & Gray & $1.9 \pm 1.7$ \\
\hline $\mathrm{BC}$ & $2.7 \pm 1.7$ & 37.8 & Light brown & $4.5 \pm 3.7$ & 55.0 & Beige & $1.1 \pm 0.7$ & 6.6 & Black & $1.1 \pm 0.5$ & 0.6 & Gray & $3.0 \pm 2.9$ \\
\hline $\mathrm{BCr}$ & $1.7 \pm 0.8$ & 32.2 & Gray & $3.6 \pm 2.8$ & 63.6 & White & $0.9 \pm 0.6$ & 2.3 & Black & $0.9 \pm 0.3$ & 1.9 & Gray & $2.4 \pm 2.2$ \\
\hline BM & $1.3 \pm 0.8$ & 42.2 & Light brown & $1.6 \pm 1.0$ & 52.0 & Gray & $0.4 \pm 0.3$ & 3.9 & Black & $0.6 \pm 0.3$ & 1.9 & Gray & $1.3 \pm 0.9$ \\
\hline
\end{tabular}

Spain (one granite) were selected (Table I). These granites were selected taking into consideration their textural characteristics, so we used granites with fine, medium and coarse grain, with homogeneous and heterogeneous textures $^{10}$ (Table I, Fig. 1).

For each rock, we calculated the general grain size and the percentages of the main mineralogical families. To accomplish this task, we performed an assessment by stereoscopic observation $(10 \times$ magnification) in scan lines in 7 $\mathrm{cm} \times 7 \mathrm{~cm}$ polished samples, which totaled at least 75 $\mathrm{cm}$ in length. The minerals are grouped (quartz, feldspars, biotite, muscovite) and evaluated in terms of size and predominant color (hue). The color was also evaluated by visual observations in the same samples.

Color was assessed with the X-Rite colorimeter (model 964), $0^{\circ}$ viewing angle geometry and specular component included, and by using the D65 illuminant. Color is expressed using CIE- $L^{*} a^{*} b^{*}$ and CIE- $L^{*} C^{*}{ }_{a b} \mathrm{~h}_{a b}$ systems. In the CIE $L^{*} a^{*} b^{*}$ system, the color is quantified according to three chromatic coordinates. The $L^{*}$-parameter represents lightness or luminosity $\left(L^{*}=0\right.$ dark; $L^{*}=100$ white), and the $a^{*}$-parameter is the red-green axis $\left(a^{*}>0\right.$ red; $a^{*}<0$ green) and the $b^{*}$-parameter is the yellow-blue axis $\left(b^{*}>0\right.$ yellow; $b^{*}<0$ blue). The attributes of the $\mathrm{CIE}-L^{*} C^{*}{ }_{a b} \mathrm{~h}_{a b} \quad$ systems are the chroma $\left(C^{*}{ }_{\mathrm{ab}}=\right.$ $\left.\left(a^{* 2}+b^{* 2}\right)^{1 / 2}\right)$ and the hue $\left(\mathrm{h}_{\mathrm{ab}}=\tan ^{-1} b^{*} / a^{*}\right)$.

The 8 - $\mathrm{mm}$ aperture was used because it is the most common in similar studies, ${ }^{6}$ except when we evaluate the influence of this factor. The $4 \mathrm{~mm}$ and $16 \mathrm{~mm}$ were also used. In this study, all the measurements were done in samples with the same superficial finishing, in this case the polished ones. The samples were evaluated in a dry condition, whereas the measurements on the slabs in the processing plant were done in a natural situation after removing the powder with a dry cloth.

In a first stage, we evaluated the color of the granites using the several slabs available in the industrial plant. The main objective was to get an idea of the color parameters and the respective changes when measured in large samples. We made 200 measurements, spaced at least 10 $\mathrm{cm}$ from each other and randomly distributed along several (2-5) granite slabs, approximately with a $200 \mathrm{~cm} \times$ $150 \mathrm{~cm}$ dimension, using the $8-\mathrm{mm}$ aperture.

Later, in a second stage, we evaluated the natural color variation of two granites, Amarelo Real and Branco Micaela, for several months. The samples $(70 \mathrm{~mm} \times 70$ $\mathrm{mm} \times 10 \mathrm{~mm}$ ) collected from different granite slabs in the industrial plant were measured with 40 locations using the 8-mm aperture.

Samples of the studied granites $(70 \mathrm{~mm} \times 70 \mathrm{~mm} \times$ $10 \mathrm{~mm}$ ) were used to study the repeatability of the color parameters, by repeating the measurements in the same samples at a different time. A total of six measurements (initial and five repetitions) were made with 40 positions, using the $8-\mathrm{mm}$ aperture, by the same person and using the same procedures.

TABLE III. Mean, standard deviation (sdv) and range $(\Delta)$ of color parameters $\left(L^{*}, a^{*}, b^{*}, C^{*}\right.$ ab and $\left.h_{\mathrm{ab}}\right)$ in studied granites (200 shots per granite; $8 \mathrm{~mm}$ aperture; granite abbreviations in Table l).

\begin{tabular}{|c|c|c|c|c|c|c|c|c|}
\hline \multirow[b]{2}{*}{ Color parameter } & \multicolumn{8}{|c|}{ Granite } \\
\hline & AR & BR & CT & PS & AT & $B C$ & $\mathrm{BCr}$ & BM \\
\hline$L^{*}$ mean & 65.38 & 55.94 & 46.67 & 62.92 & 63.69 & 60.84 & 68.30 & 60.01 \\
\hline$s d v$ & 8.84 & 10.42 & 7.86 & 5.90 & 6.91 & 9.55 & 5.47 & 4.67 \\
\hline$\Delta$ & 40.77 & 58.11 & 39.82 & 34.47 & 31.02 & 43.78 & 29.69 & 30.05 \\
\hline$a^{*}$ mean & 2.54 & 0.97 & -0.38 & -0.18 & -0.32 & 0.21 & -0.27 & -0.30 \\
\hline$s d v$ & 1.35 & 0.66 & 0.63 & 0.44 & 0.33 & 0.57 & 0.52 & 0.31 \\
\hline$\Delta$ & 6.77 & 3.70 & 4.59 & 2.21 & 1.71 & 3.51 & 3.56 & 1.98 \\
\hline$b^{\star}$ mean & 12.06 & 7.35 & 1.65 & 2.21 & 1.75 & 4.76 & 3.84 & 1.83 \\
\hline$s d v$ & 2.50 & 1.74 & 2.27 & 1.08 & 0.97 & 1.97 & 1.66 & 0.93 \\
\hline$\Delta$ & 13.07 & 10.75 & 13.15 & 5.16 & 6.20 & 10.50 & 16.63 & 5.81 \\
\hline$C^{\star}{ }_{a b}$ mean & 12.37 & 7.44 & 2.08 & 2.29 & 1.85 & 4.80 & 3.89 & 1.91 \\
\hline sdv & 2.68 & 1.74 & 2.02 & 1.02 & 0.90 & 1.95 & 1.64 & 0.86 \\
\hline$\Delta$ & 13.90 & 11.14 & 11.15 & 4.75 & 5.40 & 9.77 & 16.36 & 4.43 \\
\hline $\boldsymbol{h}_{\mathrm{ab}}$ mean & 78.69 & 82.14 & 129.50 & 100.91 & 105.33 & 88.21 & 96.04 & 104.46 \\
\hline sdv & 4.55 & 5.27 & 47.64 & 18.88 & 23.38 & 12.45 & 9.41 & 18.23 \\
\hline$\Delta$ & 21.30 & 25.89 & 198.95 & 101.32 & 161.04 & 148.53 & 68.49 & 155.38 \\
\hline
\end{tabular}




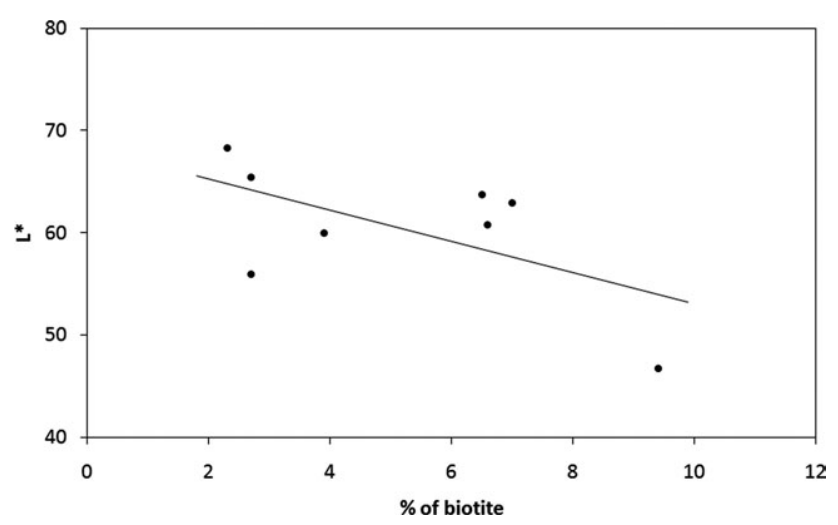

FIG. 2. Relationship between the lightness $\left(L^{*}\right)$ and the percentage of biotite.

Finally, the color of the three granites, Branco Micaela, Branco Coral and Pedras Salgadas (samples: $200 \mathrm{~mm} \times$ $100 \mathrm{~mm} \times 20 \mathrm{~mm}$ ), was evaluated in same samples with 60 random shots and using different apertures $(4 \mathrm{~mm}, 8$ $\mathrm{mm}$, and $16 \mathrm{~mm}$ ).

The statically analysis was performed with Student's t and Mann-Whitney tests by using the STATISTICA statistical program (version 9.1).

\section{RESULTS AND DISCUSSION}

\section{General Color Characteristics}

Feldspars (47.5-63.6\%) and quartz (32.2-43.1\%) are the predominant mineral families, and biotite is usually more important than muscovite (Table II). The grain size of the studied granites varies from the maximum in Branco Coral granite, to the minimum in Branco Micaela granite, and these results refer to the visual impression (see Fig. 1). The high values for the standard deviation are a consequence of the measurement procedures since scan lines do not necessarily intersect the grains at their maximum size.

The color parameters of the granites must be analyzed conscientiously due to the natural heterogeneity in terms of size and grain color. As expected, the studied granites have a light color because of the small quantities of mafic minerals, with $L^{*}$ values between $46.67 \pm 7.86$ in Cinza Telões granite, which have a higher biotite quantity, and $68.30 \pm 5.47$ in Branco Cristal granite, with a lower biotite percentage (Table III). The percentage of biotite, the only dark mineral present in the rocks studied, establishes the lightness value, and we can see in Fig. 2 that $L^{*}$ values decrease as the importance of biotite increases. Obviously, this lightness is not only influenced by the proportion of biotite, as the hue of the light minerals is also important. For instance, the quartz minerals in Branco Real granite have a grayish hue and for this reason the $L^{*}$ parameter is lower. Another aspect revealed by the results is the higher value of the $b^{*}$ parameter in Branco Coral, Branco Real, and Amarelo Real granites, according to their yellowish hue, which is more evident in the last one.
These results refer to the general perception of the color when we analyze Fig. 1, where the lightness of the Branco Cristal granite is clear, as opposed to the Cinza Telões granite, and the yellowish tonality of the Amarelo Real granite is also evident. Values of lightness are more variable as is shown both by the standard deviation and the range (diff. max.-min.) (Table III) because the granites studied have two major groups of minerals-light (quartz, feldspars, and muscovite) and dark (biotite)—and the proportion of these families changes from shot to shot while the other parameters are more stable.

These values must be considered only as indicative due the natural variations in outcrops and even in a quarry.
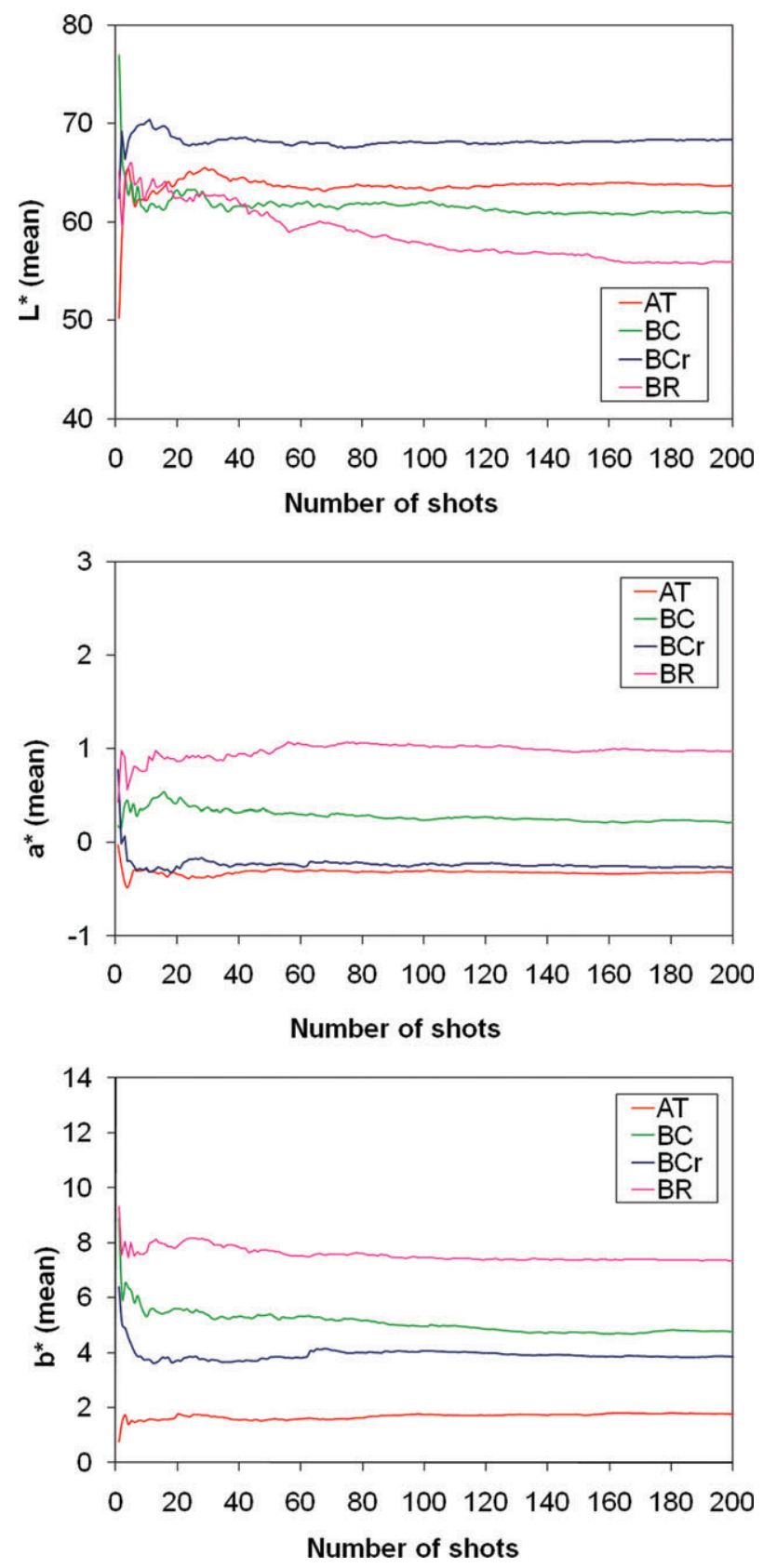

FIG. 3. Examples of $L^{*}, b^{*}$, and $a^{*}$ cumulative means in granite slabs as a function of the number of shots (granite abbreviations in Table I). 


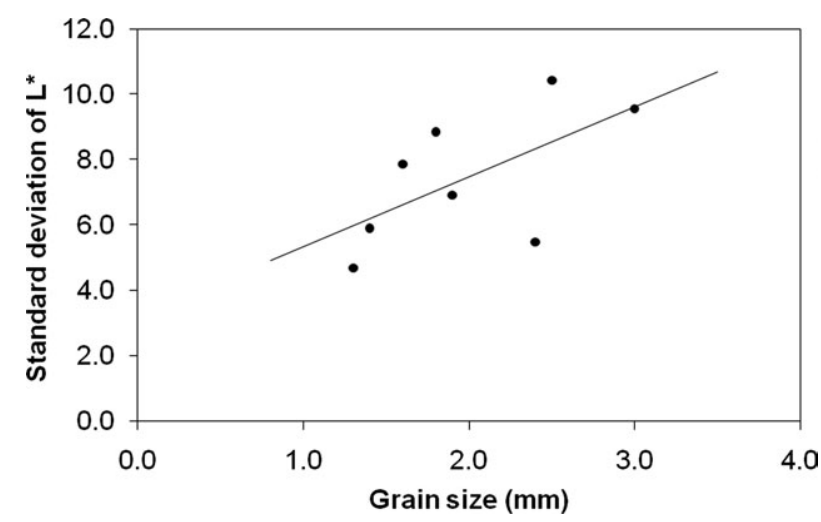

FIG. 4. Relationship between standard deviation of the $L^{*}$ parameter and the grain size in studied granites.

The mean values taken from 200 shots in several slabs are conditioned both by the variation from slab to slab and by the grain size. Usually, after $40 / 50$ shots the mean value is stable; however, there are small variations resulting from changing the place where the shots were taken (Fig. 3). In Branco Real granite, the difference between the values obtained in the first 100 shots and the others is evident, therefore the final value is a mean of two several slabs with dissimilar textural characteristics. Similar situations occur with the Branco Cristal granite (increasing of the $b^{*}$-parameter after 60 shots) and the Branco Coral granite (slight diminishing of the $b^{*}$-parameter after 80 shots).

The grain size influences the distribution of the data of the color parameters and, therefore, their standard deviation. Coarser granites need more data to get a reproducible value, whereas the finer ones could be evaluated with fewer shots. In a general way, the increase in grain size raises the standard deviation, as is shown in Fig. 4 for the $L^{*}$-parameter, and a similar relationship is found when we analyze the other color parameters. Despite the number of granites studied and the low determination coefficient, the influence of the grain size is evident in the variability of the color parameters obtained in successive shots.

These variations confirm the caution referred to above concerning the use of the mean of the color parameters in heterogenic materials like the granites. As a general rule, as the grain and/or heterogeneity increases, more shots are necessary to obtain a representative value. For the studied granites, the minimum number of shots in large slabs varies from 30 to 60 . According to the results obtained in this study, and not considering any specific particularities of the rocks, we propose 60 random shots for the determination of the color parameters in large slabs. However, the problem of the sample size remains. We used large granite slabs, whereas in laboratory studies it is only possible to use granite samples. ${ }^{5-7}$ With small samples, that is, $10 \mathrm{~cm} \times 10 \mathrm{~cm}, 40$ shots are enough, as the distribution of the measuring points is very close and the standard deviation is lower. Prieto et al. ${ }^{11}$ recommend 17 as the minimum of measurements in samples with an area of $36 \mathrm{~cm}^{2}$ for a $5-\mathrm{mm}$ aperture. When the rocks show homogeny the color characteristics are very stable and, therefore, only a few shots are needed, for instance, Benavente et al. ${ }^{5}$ studied limestones and marbles with an average of three shots. We recommend the use of several samples, but always obtained from different slabs and/or in a different location in the slabs to better represent eventual textural variations.

\section{Color Variation in Granites}

The evaluation of the variations of the color parameters in the Amarelo Real and Branco Micaela granites were carried out over a period of several months. Measurements in 103 samples (in both granites) were done in samples $(70 \mathrm{~mm} \times 70 \mathrm{~mm} \times 10 \mathrm{~mm})$ obtained at different periods to highlight the eventual impact of the intrinsic variability of the granites in their aesthetic characteristics, which are the major raw material source of the processing plant where the samples were collected. The Amarelo Real granite shows a distribution with two groups easily differentiated by the $a^{*}, b^{*}$, and $C_{\mathrm{ab}}^{*}$ parameters, as opposed to the Branco Micaela granite (Figs. 5 and 6). This granite (AR) shows color changes that are typical of high weathered granites ${ }^{12}$ with significant color variations from quarry to quarry or even in a single quarry as a consequence of the fracturing. The group of the samples with higher values of parameters $a^{*}$ and $b^{*}$, more intense chroma, belongs to a more weathered variety, whereas the other samples show less weathering.
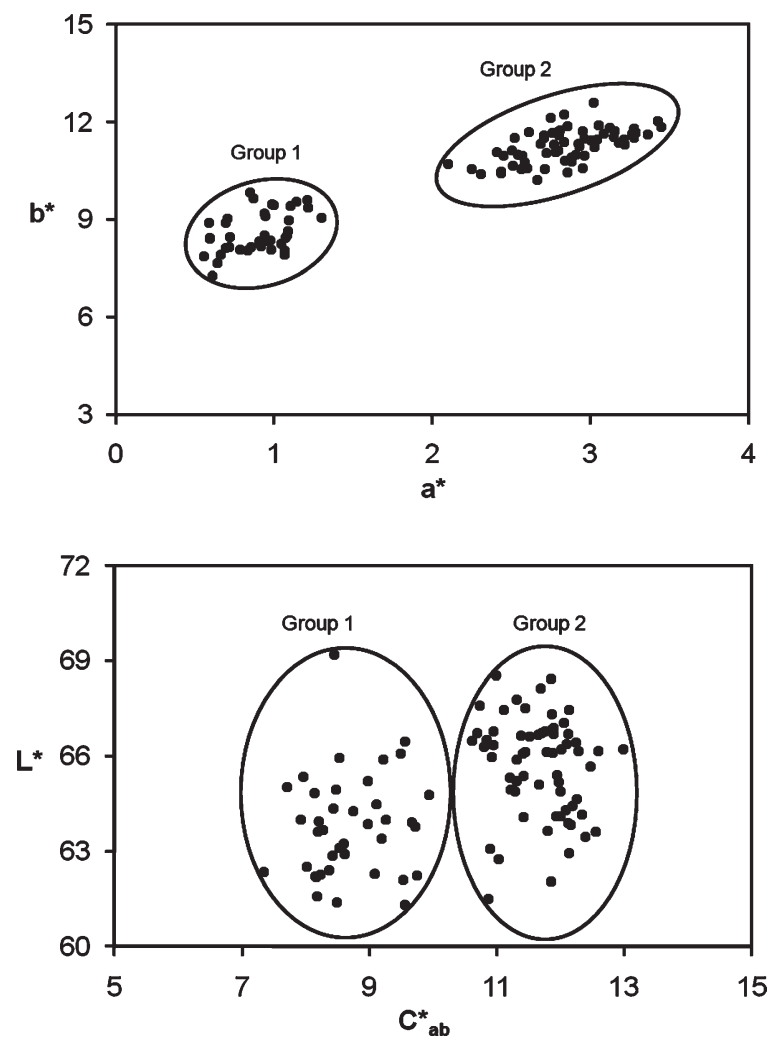

FIG. 5. Color parameters in the Amarelo Real granite (40 shots per sample; 8-mm aperture). 
TABLE IV. Comparison of the two groups identified in the Amarelo Real granite.

\begin{tabular}{cccc}
\hline Parameter & Group 1 $(n=39)$ & Group 2 $(n=64)$ & Diff. \\
\hline$L^{*}$ mean & 63.79 & 65.68 & $\Delta L^{*}=1.89$ \\
sdv & 1.63 & 1.56 & \\
$a^{*}$ mean & 0.90 & 2.85 & $\Delta a^{*}=1.95$ \\
sdv & 0.20 & 0.30 & \\
$b^{*}$ mean & 8.61 & 11.28 & $\Delta b^{*}=2.67$ \\
sdv & 0.63 & 0.51 & \\
$C^{*}$ ab mean & 8.70 & 11.67 & $\Delta C^{*}{ }_{\text {ab }}=2.97$ \\
sdv & 0.64 & 0.54 & $\Delta h_{\mathrm{ab}}=7.85$ \\
$h_{\mathrm{ab}}$ mean & 84.32 & 76.47 & \\
sdv & 1.19 & 1.19 & \\
\hline
\end{tabular}

For the Amarelo Real granite the values of the $C^{*}$ parameter are more differentiating than the $L^{*}$ values, as the first (color saturation) leads us to the easily identification of the two distinguishing groups, whereas the second (lightness) does not allow the same. Likewise, the values of parameters $a^{*}$ and $b^{*}$ are also successful in group differentiation (Table IV). More important than the statistically significance of the color parameters is the total color difference $\left(\Delta E_{\mathrm{ab}}^{*}\right)$ computed by applying the formula $\Delta E_{\mathrm{ab}}^{*}=\left(\Delta L^{* 2}+\Delta a^{* 2}+\Delta b^{* 2}\right)^{1 / 2} .^{13}$ The two groups identified in Amarelo Real granite have an $\Delta E_{\mathrm{ab}}^{*}=3.81$, higher than 3 CIELAB units, the upper limit of rigorous color tolerance. ${ }^{14,15}$ It is clear that this methodology and equipment make it possible to highlight color variations during the processing operations in the plant and thus avoid significant differences in the color of granite slabs applied in the same building. This is a problem found in large structures where the origin of raw material could be from more than one quarry. Therefore, in addition to the natural color variation of the weathering granites, we must also consider the changes (in color, shape, and grain size) of the granite outcrop.
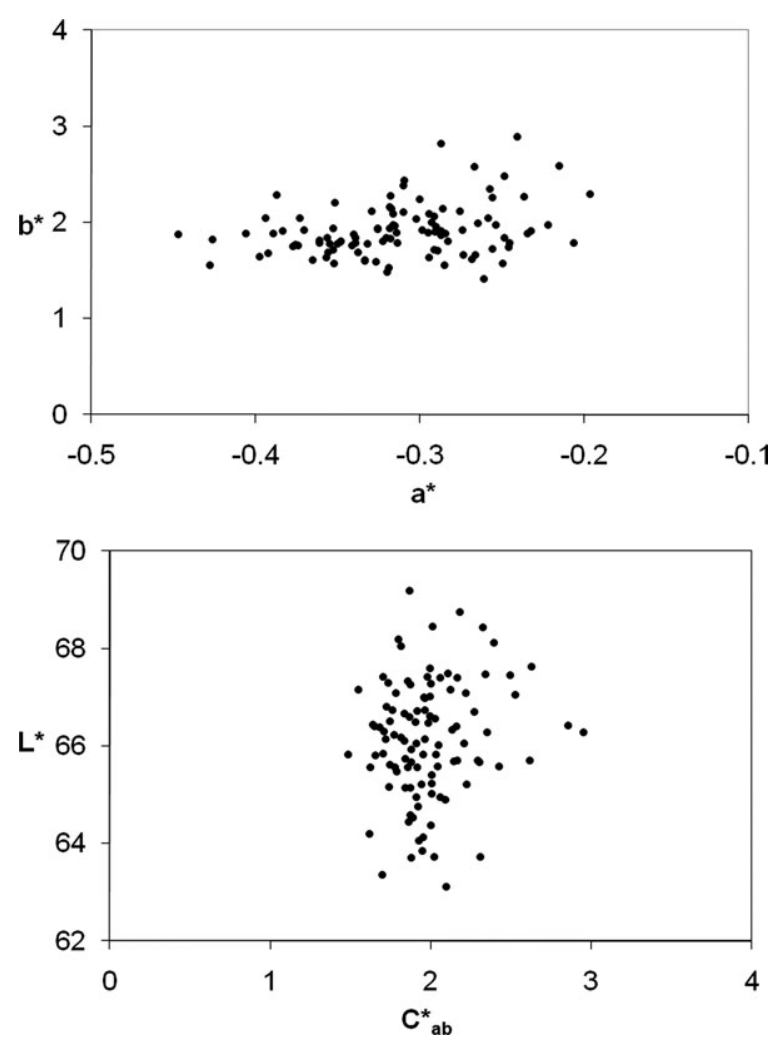

FIG. 6. Color parameters in the Branco Micaela granite (40 shots per sample; 8-mm aperture).

The Branco Micaela granite, a typical grayish granite, has low values of $a^{*}, b^{*}$, and $C_{\text {ab }}^{*}$ parameters; therefore it is close to chromatic neutrality, showing small variations. Although the $L^{*}$ values have some variation as a consequence of biotite distribution, this does not enable us to make any distinction among the studied samples. Color variation in grayish granites with values of $a^{*}$ and $b^{*}$

TABLE V. Variations of the color parameters by repeating measurements in the same sample (40 shots per sample; $8 \mathrm{~mm}$ aperture; granite abbreviations in Table I).

\begin{tabular}{|c|c|c|c|c|c|c|c|c|}
\hline & \multicolumn{8}{|c|}{ Granites } \\
\hline & AR & $\mathrm{BR}$ & CT & PS & AT & BC & $\mathrm{BCr}$ & BM \\
\hline$L^{*}$ initial & 59.94 & 64.32 & 56.12 & 65.64 & 60.96 & 67.59 & 71.05 & 65.54 \\
\hline 1 & $0.38^{\mathrm{a}}$ & $1.31^{a}$ & $-0.85^{a}$ & $-0.52^{\mathrm{a}}$ & $0.43^{\mathrm{a}}$ & $1.15^{\mathrm{a}}$ & $0.18^{a}$ & $1.86^{\mathrm{a}}$ \\
\hline$\Delta L^{*} 2$ & $1.19^{\mathrm{a}}$ & $1.94^{\mathrm{a}}$ & $0.37^{\mathrm{a}}$ & $1.43^{\mathrm{a}}$ & $-0.43^{\mathrm{a}}$ & $0.75^{\mathrm{a}}$ & $0.01^{a}$ & $-0.60^{\mathrm{a}}$ \\
\hline 3 & $1.88^{a}$ & $1.33^{a}$ & $-0.78^{a}$ & $-0.30^{\mathrm{a}}$ & $0.86^{\mathrm{a}}$ & $0.54^{a}$ & $1.52^{\mathrm{a}}$ & $0.95^{\mathrm{a}}$ \\
\hline 4 & $1.40^{\mathrm{a}}$ & $1.53^{\mathrm{a}}$ & $-0.74^{\mathrm{a}}$ & $-0.42^{\mathrm{a}}$ & $1.35^{\mathrm{a}}$ & $1.42^{\mathrm{a}}$ & $1.47^{\mathrm{a}}$ & $0.96^{\mathrm{a}}$ \\
\hline 5 & $0.04^{a}$ & $0.31^{a}$ & $0.68^{a}$ & $1.02^{\mathrm{a}}$ & $-1.72^{\mathrm{a}}$ & $1.32^{a}$ & $0.79^{a}$ & $2.32^{b}$ \\
\hline$a^{*}$ initial & 1.62 & 0.71 & -0.50 & -0.31 & -0.36 & -0.02 & -0.31 & -0.40 \\
\hline 1 & $-0.25^{\mathrm{a}}$ & $1.18^{\mathrm{a}}$ & $0.05^{a}$ & $0.00^{\mathrm{a}}$ & $0.01^{\mathrm{a}}$ & $-0.05^{a}$ & $0.04^{a}$ & $0.03^{\mathrm{a}}$ \\
\hline$\Delta a^{*} 2$ & $0.04^{a}$ & $1.20^{\mathrm{a}}$ & $0.02^{\mathrm{a}}$ & $-0.01^{\mathrm{a}}$ & $0.01^{\mathrm{a}}$ & $0.09^{\mathrm{a}}$ & $0.18^{\mathrm{a}}$ & $0.09^{\mathrm{a}}$ \\
\hline 3 & $0.12^{\mathrm{a}}$ & $1.38^{\mathrm{a}}$ & $0.03^{a}$ & $0.07^{\mathrm{a}}$ & $-0.02^{\mathrm{a}}$ & $0.01^{\mathrm{a}}$ & $0.00^{\mathrm{a}}$ & $-0.01^{\mathrm{a}}$ \\
\hline 4 & $0.00^{\mathrm{a}}$ & $1.32^{\mathrm{a}}$ & $0.09^{a}$ & $-0.02^{\mathrm{a}}$ & $0.02^{\mathrm{a}}$ & $0.04^{a}$ & $0.02^{\mathrm{a}}$ & $0.01^{\mathrm{a}}$ \\
\hline 5 & $0.19^{a}$ & $1.30^{\mathrm{a}}$ & $0.02^{a}$ & $-0.10^{a}$ & $0.06^{a}$ & $0.02^{\mathrm{a}}$ & $0.00^{\mathrm{a}}$ & $-0.05^{a}$ \\
\hline$b^{\star}$ initial & 10.15 & 5.59 & 1.75 & 2.00 & 1.28 & 4.14 & 2.98 & 1.58 \\
\hline 1 & $-0.28^{a}$ & $0.43^{a}$ & $-0.32^{\mathrm{a}}$ & $0.04^{a}$ & $-0.43^{\mathrm{b}}$ & $0.36^{\mathrm{a}}$ & $0.01^{a}$ & $0.07^{\mathrm{a}}$ \\
\hline$\Delta b^{*} 2$ & $0.10^{\mathrm{a}}$ & $0.22^{\mathrm{a}}$ & $-0.11^{\mathrm{a}}$ & $0.19^{a}$ & $-0.25^{a}$ & $0.67^{\mathrm{a}}$ & $0.46^{a}$ & $0.37^{\mathrm{a}}$ \\
\hline $\begin{array}{ll}2 \\
3\end{array}$ & $0.62^{\mathrm{a}}$ & $0.40^{\mathrm{a}}$ & $-0.21^{a}$ & $0.31^{a}$ & $-0.30^{\mathrm{a}}$ & $0.44^{\mathrm{a}}$ & $-0.8^{\mathrm{a}}$ & $0.20^{\mathrm{a}}$ \\
\hline 4 & $0.50^{\mathrm{a}}$ & $0.39^{a}$ & $-0.38^{\mathrm{a}}$ & $0.11^{a}$ & $-0.28^{a}$ & $0.72^{\mathrm{a}}$ & $0.26^{a}$ & $0.39^{b}$ \\
\hline 5 & $0.72^{\mathrm{a}}$ & $0.50^{\mathrm{a}}$ & $-0.04^{\mathrm{a}}$ & $0.21^{\mathrm{a}}$ & $0.11^{\mathrm{a}}$ & $0.35^{\mathrm{a}}$ & $0.27^{a}$ & $0.27^{\mathrm{a}}$ \\
\hline
\end{tabular}

a not significant changes.

b significant changes at $p<0.05$. 


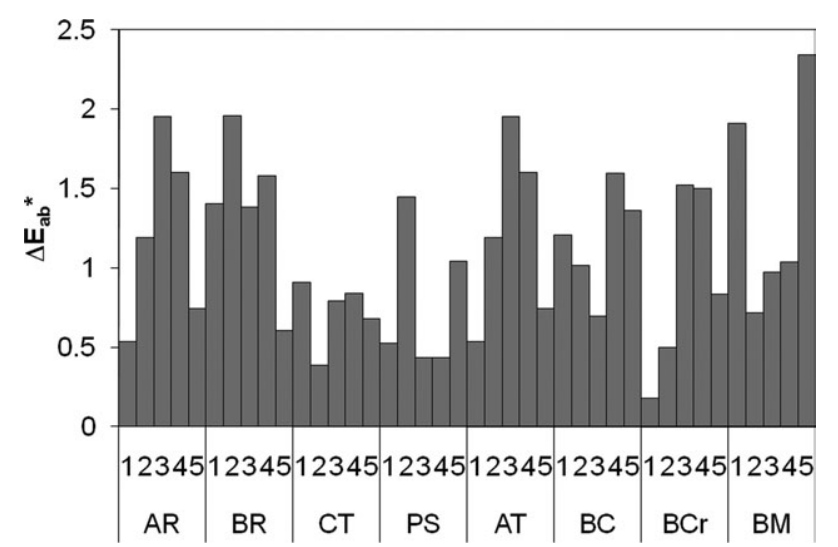

FIG. 7. Values of $\Delta E^{\star}$ ab of the five repetitions made in each sample (40 shots per sample; $8-\mathrm{mm}$ aperture; granite abbreviations in Table I).

close to zero are not easily distinguishable with a colorimeter, as the changes in the proportions of mineral species only provide modifications in the lightness or clarity. In the Branco Micaela granite, the $L^{*}$ values had an inter-

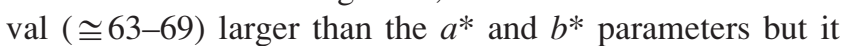
is not possible to define groups. This granite is very homogeneous, and this method should be applied instead of other coarser/more heterogeneous granites to identify possible larger variations. Another aspect emphasized by the results is the difference in the $L^{*}$-parameter when we compare the data obtained in large slabs $\left(L^{*}=60.01 \pm\right.$ 4.67; Table III) with the value obtained from samples $\left(L^{*}=64.97 \pm 1.83\right.$; Fig. 6). This difference is statistically significant ( $t$-value: 13.18 ; df: 286 ; $p$-value: 0.000 ) however, there is no evident reason for that difference. The cleaning state and/or humidity could be the cause, but only further research will highlight the doubt.

These data are very important to evaluate the change of the color in the rock pieces applied over the last decades. The granites and other rocks change their coloration over time due to the action of environmental factors. ${ }^{6,8,16-19}$ To evaluate if the changes are significant, we need to know the color parameters and their natural variations.

The consistency of the color parameters were evaluated by repeating the measures in the same samples. The reproducibility was evaluated with six measurements by the computation of the $L^{*}, a^{*}$, and $b^{*}$ differences from the values obtained in the first measurement (Table V), which are not significant in most of the cases. The total color difference $\left(\Delta E^{*}{ }_{\mathrm{ab}}\right)^{13}$ was computed considering as a pattern the values of $L^{*}, a^{*}$ and $b^{*}$ obtained in the first measurement. $\Delta E_{\mathrm{ab}}^{*}$ values will be as high as the differences of parameters $L^{*}, a^{*}$ and $b^{*}$ increase. In the granites used in this study, the variation of the color parameters is small and therefore the $\Delta E_{\mathrm{ab}}^{*}$ values are low, with small amplitude (Fig. 7), and lower than 3 CIELAB units, the upper limit of rigorous color tolerance. ${ }^{14,15}$

As a general rule, and considering these granites and this methodology, we can state that $\Delta E_{\mathrm{ab}}^{*}$ values lower than 2.5 are not aesthetically relevant; however, these issue must be studied in more samples to evaluate the influence of the tex- tural characteristics, since, for instance the Branco Micaela granite, with the finer grain and the most homogeneous texture, has the highest value of $\Delta E_{\mathrm{a} b}^{*}$. These results are very important, and reveal the need for a similar evaluation whenever it is necessary to quantify the color variation, for instance, after a clean or impermeable treatment. ${ }^{4,6,7}$

\section{Influence of the Aperture}

The aperture seems not to have any influence in the values of the chromatic parameters of the granites Branco
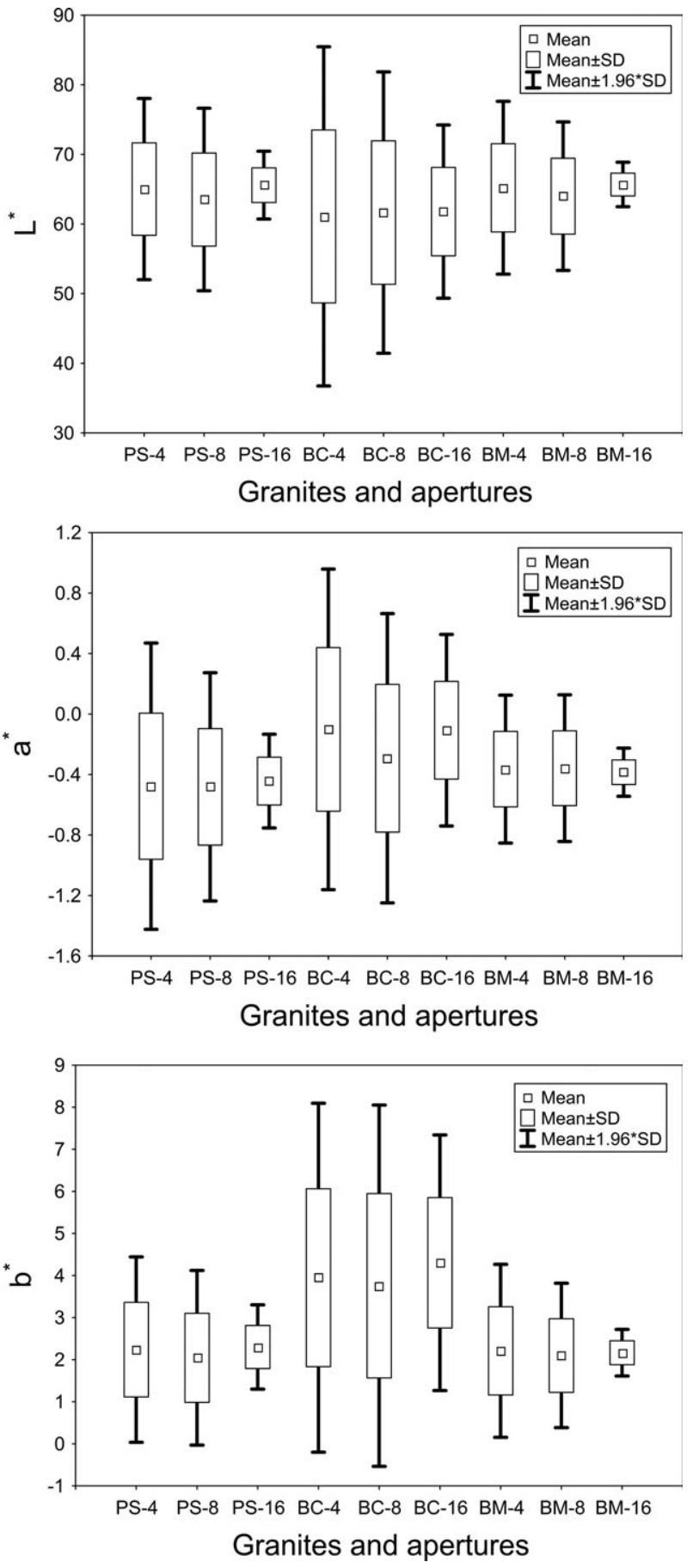

FIG. 8. Influence of the aperture in color parameters of the Pedras Salgadas (PS), Branco Coral (BC) and Branco Micaela (BM) granites (60 shots per measure). 
TABLE VI. Differences of color parameters with different pairs of measurement heads (60 shots per measure).

\begin{tabular}{lcccc}
\hline Granite & Apertures & $L^{*}$-Diff. & $a^{*}$-Diff. & $b^{*}$-Diff. \\
\hline Pedras Salgadas & $4-8$ & $1.50^{\mathrm{a}}$ & $0.00^{\mathrm{a}}$ & $0.19^{\mathrm{a}}$ \\
& $4-16$ & $0.56^{\mathrm{a}}$ & $0.03^{\mathrm{a}}$ & $0.06^{\mathrm{a}}$ \\
Branco Coral & $8-16$ & $2.06^{\mathrm{a}}$ & $0.04^{\mathrm{a}}$ & $0.26^{\mathrm{a}}$ \\
& $4-8$ & $0.55^{\mathrm{a}}$ & $0.19^{\mathrm{a}}$ & $0.19^{\mathrm{a}}$ \\
& $4-16$ & $0.69^{\mathrm{a}}$ & $0.01^{\mathrm{a}}$ & $0.19^{\mathrm{a}}$ \\
Branco Micaela & $8-16$ & $0.14^{\mathrm{a}}$ & $0.19^{\mathrm{b}}$ & $0.55^{\mathrm{b}}$ \\
& $4-8$ & $1.21^{\mathrm{a}}$ & $0.01^{\mathrm{a}}$ & $0.11^{\mathrm{a}}$ \\
& $4-16$ & $0.47^{\mathrm{a}}$ & $0.02^{\mathrm{a}}$ & $0.04^{\mathrm{a}}$ \\
& $8-16$ & $1.68^{\mathrm{b}}$ & $0.03^{\mathrm{a}}$ & $0.07^{\mathrm{a}}$ \\
\hline
\end{tabular}

a not significant changes.

${ }^{\mathrm{b}}$ significant changes at $p<0.05$.

Coral, Branco Micaela, and Pedras Salgadas and the differences are almost not significant (there are two significant differences) (Fig. 8; Table VI). With the exception of the $L^{*}$-parameter, which have higher differences, the others parameters show very similar values with the evaluated apertures $(4 \mathrm{~mm}, 8 \mathrm{~mm}$, and $16 \mathrm{~mm})$. The differences of the $L^{*}$-parameter in Branco Micaela and Pedras Salgadas granites are higher than expected and may be a consequence of an abnormal distribution of white minerals (feldspars and quartz) and/or dark minerals (biotite) in the studied sample. The $L^{*}$-parameter value in those granites, which is lower with the 8 -mm aperture, could be influenced by the distributions of the shots along the sample. Eventually, we see a larger concentration of the dark minerals (biotite in this case) along the samples where the measurements were made. Despite such influence, if it does in fact occur, the differences should be more evident in the measurements made with the lower aperture, $4 \mathrm{~mm}$. It must be noted that the variation of the color parameters obtained from the three apertures is similar to the variations found from different measurements in the same sample, so these values may be considered as normal. Although the difference in $L^{*}$-parameter is lower $(\cong 2)$, this matter must be investigated with more detail to highlight the causes of such variations.

The total color differences $\left(\Delta E_{\mathrm{ab}}^{*}\right)$ are lower than the upper limit of rigorous color tolerance referred to above (3 CIELAB units) (Fig. 9) and the same conclusion was found in a similar evaluation with four measurement heads $(5,8,10$, and $50 \mathrm{~mm}) .{ }^{11}$

The advantage of using larger apertures is in the error of the mean values. So, for the number of the shots made in each color measurement, (60) we verify a decrease of about

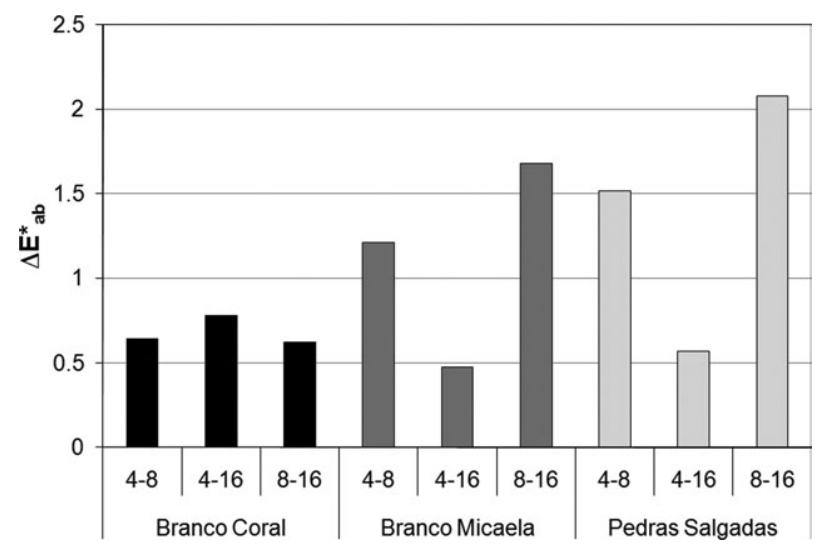

FIG. 9. Total color differences with different pairs of measurement heads in Branco Coral, Branco Micaela and Pedras Salgadas granites (60 shots per measure).

$50 \%$ from the standard deviation from the 4-mm aperture to the 16-mm aperture (Table VII). And obviously, the coarser granite, Branco Coral, has a standard deviation higher than the other two granites. We recommend, therefore, the use of the larger aperture, especially when the samples have large surfaces. The larger apertures make it possible to obtain the color parameters with a lower number of shots for a given standard deviation, as pointed out in a recent published work $^{11}$. When the samples have a small size, it is more useful to use smaller apertures to create a more uniform distribution of the position of the shots. When it is necessary to highlight the variations among one sample, that is, the heterogeneity of the granite, the 4-mm aperture is more adequate, especially when the minerals have a reduced area.

\section{CONCLUSIONS}

This work carries out an analysis of some factors that should be considered in the color evaluation of granites used as ornamental stones. Granites are heterogeneous concerning the grain size and the distribution of the mineral families along the surfaces, and these natural variations must be considered when the color parameters are evaluated to limit their influence on the color characterization.

Lightness of the granites is influenced by the proportion of biotite, but the hue of the light minerals, like quartz with a grayish hue, is also an important factor which conditions the final value. Evaluation of the chromatic coordinates in large polished slabs should be carried out after 60 randomly distributed shots.

TABLE VII. Standard deviation of the color parameters from measurements with different apertures (60 shots per measure).

\begin{tabular}{|c|c|c|c|c|c|c|c|c|c|}
\hline \multirow{2}{*}{$\begin{array}{l}\text { Color } \\
\text { parameters }\end{array}$} & \multicolumn{3}{|c|}{ Branco Coral } & \multicolumn{3}{|c|}{ Branco Micaela } & \multicolumn{3}{|c|}{ Pedras Salgadas } \\
\hline & $4 \mathrm{~mm}$ & $8 \mathrm{~mm}$ & $16 \mathrm{~mm}$ & $4 \mathrm{~mm}$ & $8 \mathrm{~mm}$ & $16 \mathrm{~mm}$ & $4 \mathrm{~mm}$ & $8 \mathrm{~mm}$ & $16 \mathrm{~mm}$ \\
\hline$L^{*}$ & 12.43 & 10.31 & 6.35 & 6.33 & 5.44 & 1.63 & 6.64 & 6.68 & 2.49 \\
\hline$a^{*}$ & 0.54 & 0.49 & 0.32 & 0.25 & 0.25 & 0.08 & 0.48 & 0.39 & 0.16 \\
\hline$b^{*}$ & 2.12 & 2.19 & 1.55 & 1.05 & 0.88 & 0.28 & 1.12 & 1.06 & 0.51 \\
\hline$C^{* a b}$ & 2.09 & 2.14 & 1.53 & 0.99 & 0.78 & 0.27 & 1.03 & 0.88 & 0.47 \\
\hline$h_{\mathrm{ab}}$ & 12.54 & 13.50 & 7.12 & 16.56 & 21.58 & 2.98 & 18.35 & 25.10 & 6.76 \\
\hline
\end{tabular}


Color evaluation over time gives different results for the grayish granites and the granites with some hue, like the yellowish ones. The granites close to chromatic neutrality only show variation of $L^{*}$-parameter essentially as consequence of biotite distribution and therefore it is not possible to identify distinguishable groups. Otherwise, it is possible to distinguish color variation over time in weathered granites, which apparently is not identified in the processing plant but is statistically significant and important for commercial purposes. Therefore, the colorimeter is very useful in quality control to avoid significant color variation during the application in building, because raw material are usually used from different quarries.

Color reproducibility was performed by repetition of color evaluation in same samples, and for the studied granites a total color difference $\left(\Delta E^{*}{ }_{\mathrm{ab}}\right)$ over 2.5 reveal chromatic variations. This threshold is influenced by the textural characteristics of the granites and must always be established beforehand whenever there is a need to evaluate the color variation in granites.

Color parameters do not show a significant discrepancy with different heads of measurement, but the 16-mm aperture allows a decrease in the standard deviation of the mean values and should be used for obtaining the color parameters quickly.

This investigation was carried out based on samples obtained in a processing plant; for this reason, the results could be useful for the implementation of a quality control system of the chromatic quality in final products. Nevertheless, the textural specificity of the rocks under evaluation must always be considered before applying this methodology.

\section{ACKNOWLEDGEMENTS}

The authors are grateful to the Centro de Geociências-Universidade de Coimbra for providing partial financial support for this study, and also to the anonymous reviewers for their constructive comments and suggestions.

1. Sousa LMO, Suárez del Río LM, Calleja L, Ruiz de Argandoña V, Rey AR. Influence of microfractures and porosity on the physicomechanics properties and weathering of ornamental granites. Eng Geol 2005;77:153-168.
2. Huang $H, X u X P$. Interfacial interactions between diamond disk and granite during vertical spindle grinding. Wear 2004;256:623-629.

3. Carvalho JF. Henriques P, Falé P, Luís G. Decision criteria for the exploration of ornamental-stone deposits: Application to the marbles of the Portuguese Estremoz Anticline. Int J Roc Mech Min Sci 2008;45:1306-1319.

4. Iñigo AC, Vicente-Tavera S, Rives V, Vicente MA. Color Changes in the surface of granitic materials by consolidated and/or water repellent treatments. Color Res Appl 1997;22:133-141.

5. Benavente D, Martínez-Verdú F, Bernabeu A, Viqueira V, Fort R, García del Cura MA, Illueca C, Ordóñez S. Influence of surface roughness on color changes in building stones. Color Res Appl 2003;28:443-351.

6. Grossi CM, Brimblecombe P, Esbert RM, Alonso FJ. Color changes in architectural limestones from pollution and cleaning. Color Res Appl 2007;32:320-331.

7. Grossi CM, Alonso FJ, Esbert RM, Rojo A. Effect of laser cleaning on granite color. Color Res Appl 2007;32:152-159.

8. Bams V, Dewaele S. Staining of white marble. Mat Character 2007;58:1052-1062.

9. Dalal EN, Natale-Hoffman KM. The effect of gloss on color. Color Res Appl 1999;24:369-376.

10. Sousa LMO, Gonçalves BMM. Avaliação da cor em rochas graníticas In Coke C, Sousa L, Lourenço JM, Sousa Oliveira A, Baptista JC, Abreu ME, editors. V Seminário Recursos Geológicos, Ambiente e Ordenamento do Território. Vila Real: UTAD; 2008. p 39-43.

11. Prieto B, Sanmartín P, Silva B, Martínez-Verdú F. Measuring the color of granite rocks: A proposed procedure. Color Res Appl 2010;35:368-375.

12. Sousa LMO, Oliveira A, Lourenço J. Proposta de área para a exploração de granito na região da Falperra (NE de Portugal). In José Mirão J, Balbino A, editors. VII Congresso Nacional de Geologia. Estremoz: Universidade de Évora; 2006. p 1063-1066.

13. Sève R. New formula for the computation of CIE 1976 hue difference. Color Res Appl 1991;16:217-218.

14. Berns RS. Billmeyer and Saltzman's principles of color technology, 3rd edition. New York: Wiley; 2000.

15. Völz HG. Industrial color testing. Weinheim: Wiley-VCH; 2001.

16. Hajpál M, Török Á. Mineralogical and colour changes of quartz sandstones by heat. Env Geol 2004;46:311-322.

17. Török Á, Hajpál M. Effect of temperature changes on the mineralogy and physical properties of sandstones. A laboratory study. Rest Buil Monum 2005;11:211-218.

18. Begonha A. Mineralogical study of the deterioration of granite stones of two Portuguese churches and characterization of the salt solutions in the porous network by the presence of diatoms. Mat Character 2009;60:621-635.

19. Alonso FJ, Vázquez P, Esbert RM, Ordaz J. Ornamental granite durability: Evaluation of damage caused by salt crystallization test. Mater Construcc 2008;58:191-201. 